\title{
The invasiveness of Entamoeba histolytica - a continuing enigma
}

\author{
J P Ackers
}

\section{Introduction}

In 1875 Lösch described the case of a . Jung farmer who had been admitted to his clinic in St Petersburg, Russia, two years earlier. The man had been suffering from chronic dysentery and Lösch found such large numbers of amoebae in his faeces that he became convinced that they were responsible for the disease. He named the organism Ameba coli and showed that it produced colonic ulceration and dysentery in dogs. This patient was the first known to have died from amoebiasis and subsequent work by a number of investigators established that the organism had a simple life cycle, involving a motile trophozoite and a resistant, usually quadrinucleate, cyst and could spread away from the intestine; the name Entamoeba histolytica also became established. ${ }^{1}$ Other, non-pathogenic, species of amoeba (such as $E$ coli) were also defined and the unique invasiveness of $E$ histolytica-its ability to penetrate the wall of the human large bowel and disseminate via the blood stream to the liver and other organs-has been the subject of investigation ever since. In recent times the pace of this investigation has noticeably quickened and the purpose of this short paper is to summarise some recent developments in our understanding of how and why $E$ histolytica spreads through the body. It is in no sense exhaustive and the still indispensable monograph edited by Ravdin ${ }^{2}$ and more recent reviews $^{3-6}$ should be consulted for further details. As the title indicates, much about this fascinating organism remains obscure.

\section{Entamoeba histolytica and E dispar}

Open any but the most recent of medical textbooks and you will probably find the following statement in some form or other: "There are approximately 500 million new infections with $E$ histolytica, world-wide, each year, of whom $10 \%$ at most will suffer from clinical disease. ${ }^{7}$ These 50 million or so patients will be affected by invasive amoebiasis in which the organism disseminates from the lumen of the large bowel causing ulceration of the mucosa and bloody diarrhoea (amoebic dysentery), more rarely invades the liver (causing hepatic amoebiasis, commonly known as amoebic liver abscess) and occasionally attacks other organs. This invasive disease kills between 40 and 100 thousand people each year, almost all in developing countries. The remaining 450 million cases of amoebiasis will comprise seronegative, asymptomatic cyst passers...".
For many years it was far from clear whether the outcome of infection resulted from differences in host or parasite, but since the pioneering observation of Martinz-Palomo $\mathrm{et} \mathrm{al}{ }^{8}{ }^{8}$ it has become more and more apparent that there are fundamental biochemical, immunological and genetic differences between the organisms recovered from patients with invasive disease and those parasitising asymptomatic cyst passers. The proposal ${ }^{\circ}$ that the invasive and non-invasive organisms were best regarded as separate species (rRNA sequence differences suggest that they are about as different as humans and mice) with the name $E$ histolytica retained for the one causing clinical disease and the designation $E$ dispar revived for the amoeba recovered from asymptomatic cyst passers is now almost universally accepted and is adopted here. It is important realise that the cysts of the two species are morphologically indistinguishable.

This new insight is far more than simple taxonomic nit-picking for it means that much of the amoebiasis literature needs to be reinterpreted - to give but two examples, it now seems likely that the majority of those infected with $E$ histolytica will suffer some degree of illness and an experiment looking for genomic differences between "invasive and non-invasive strains" of $E$ histolytica has probably been comparing two different species.

\section{Pathogenicity and virulence}

These two terms are often used loosely and/or synonymously but are probably best defined for our purpose ${ }^{10}$ as follows:

- disease is a measurable departure from the normal condition;

- a pathogen is an organism capable of causing disease;

- virulence is the relative capacity of a pathogen to cause disease. ${ }^{11}$

Thus, in principle, pathogenicity is an unqualifiable term - an organism either causes disease or it does not-while virulence can range from low to high depending on the severity of the resulting illness. Of course, it is very unusual for any pathogen to cause a uniform level of damage in everyone infected and low virulence can mean either mild disease in most patients or more severe illness in a minority. Only under experimental conditions is it usually possible to say whether these different results relate to host variability, the existence amongst a pathogen of strains of differing virulence, or both. 
In the case of the Entamoeba, $E$ dispar is regarded by some as non-pathogenic and by others as a pathogen of almost no virulence. ${ }^{12}{ }^{13}$ $E$ histolytica is clearly a pathogen but the proportion of those infected who are asymptomatic is unclear. Ravdin ${ }^{6}$ suggests that it may be as high as $90 \%$ but a figure this large makes it very hard to understand how Sargeaunt and Williams were able to obtain a near-perfect correlation between the detection (by culture) of organisms with a "pathogenic" zymodeme (that is, E histolytica) and the presence of clinical symptoms in nearly 6000 samples from different parts of the world. ${ }^{14}$ Extensive studies by Jackson et al in South Africa have shown that these asymptomatic carriers may proceed to frank illness or may spontaneously lose the infection; significantly, however, all cases were seropositive.$^{15-17}$ Long term carriage of $E$ dispar without seroconversion undoubtedly occurs and it is possible that highly immunogenic parasite molecules can only gain access to the host's immune system if at least minimal damage to the mucosa has taken place.

Many recent attempts to understand how $E$ histolytica is able to invade have compared its proteins and enzymes, genes and mRNAs with less virulent amoebae; these "controls" have included organisms which we now know to be different species ( $E$ dispar and $E$ moshkovskii, the former "Laredo" or " $E$ histolytica-like" strains ${ }^{18}$ ). Alternatively, comparisons have been made amongst a range of laboratory isolates of $E$ histolytica growing axenically (that is, in the absence of bacteria or other living organisms) which have high or low virulence when measured in vitro or in laboratory animals. There are weaknesses with both approaches: applying the first, how to tell which of the many detectable differences are actually significant while in the second case the use of axenic cultures brings its own problems. All large bowel amoebae normally live in an intimate relation with a very complex bacterial flora; the process of axenisation involves intense and prolonged selection pressure, ${ }^{19}$ which is known to affect proteinase levels, ${ }^{20} 21$ the expression of epitopes $^{22}{ }^{23}$ and virulence in vitro. ${ }^{24}$ It is not actually known whether in vitro or small animal measures of virulence detect differences which are significant in human disease nor, in fact, whether naturally occurring $E$ histolytica differ in virulence at all-variation in disease severity could result from host factors and human volunteer studies ${ }^{25}$ have shown that cysts from a single patient can produce both dysentery and asymptomatic amoebiasis in different recipients.

How does $E$ histolytica invade?

The process whereby a luminal parasite arrives in the liver is conventionally divided into six stages: adherence, target cell killing (cytotoxicity), dissolution of the basement membrane, ingestion of cell fragments and erythrocytes (phagocytosis), egress into the circulation, and finally, establishment of foci of infection in the liver. Our knowledge of the molecular mecha- nisms underlying these processes declines steadily going from first to last.

\section{Adherence}

$E$ histolytica trophozoites express a number of molecules which mediate attachment to enterocytes, of which by far the best studied is the galactose/ $\mathrm{N}$-acetyl galactosamine inhibitable lectin (GIL). It is not known whether this adherence is simply a precursor to invasion or a necessity to prevent the parasite being swept away with the bowel contents, but the presence of a homologue of the GIL gene in $E$ dispar would support the latter role. The GIL is a heterodimeric molecule comprised of a heavy $(170 \mathrm{kDa})$ and light $(35 \mathrm{kDa})$ subunit; at least five heavy and possibly six light subunit genes are known, ${ }^{26}$ but at present all known biological functions seem to be located on the heavy subunit. These functions are extraordinarily diverse and include, as well as adherence, involvement in contact mediated cytotoxicity and resistance to complement lysis (see later), making GIL a key virulence factor. Yet anomalies remain; the carbohydrate recognised is present in colonic mucin as well as on the surface of epithelial cells and mucin prevents the in vitro binding of $E$ histolytica to target cells very effectively. ${ }^{27}$ In the gerbil model, mucus depletion precedes epithelial erosion ${ }^{28}$ and a heat stable secretagogue has been detected in axenic cultures of $E$ histolytica. ${ }^{29}{ }^{30}$ It is plausible that the latter activity is involved in the invasion process by facilitating adherence of trophozoites to the mucosa. Whether $E$ dispar produces this as yet uncharacterised molecule is not known. It is likely, however, that the GIL homologue of the latter can mediate adherence to colonic epithelium as two anti-GIL monoclonal antibodies which enhance lectin mediated adherence to target cells recognise the only epitopes (Nos. $1 \& 2$ ) which are also present on $E$ dispar trophozoites. $^{31}{ }^{32}$ The cloning of secretagogue and lectin genes from $E$ dispar will clearly shed much new light on the early stages of pathogenesis.

Other molecules mediating adherence have been described and may be less studied rather than less important than GIL; the ability of galactose to inhibit almost all binding and cytotoxicity argues against the former. A monoclonal antibody directed against a surface glycoconjugate inhibited binding and cytotoxicity $^{33}$; a $112 \mathrm{kDa}$ adhesin ${ }^{34}$ also possesses proteinase activity. ${ }^{35}$ No corresponding functional molecule can be detected in $E$ dispar. ${ }^{36}$ Finally, a $220 \mathrm{kDa}$ lectin ${ }^{37}$ also exists whose binding is inhibited by polymers of $\mathrm{N}$-acetyl glucosamine.$^{38}$ These last two molecules and GIL will mediate the binding of $E$ histolytica to red blood cells and erythrophagocytosis, which are much studied properties of this parasite (see later). Although in vitro both $E$ dispar and the non-pathogenic $E$ coli ingest erythrocytes, in vivo haematophagous trophozoites are found only in the faeces of patients with invasive disease caused by $E$ histolytica. The benefits which this species obtains from its ability to penetrate the mucosa are obscure at best (see later); however, it is possible that ingestion of red cells 
provides a source of iron, which is an absolute requirement for $E$ histolytica. ${ }^{39} 40$ Other molecules may be involved in binding to erythrocytes, as the process is most effectively inhibited by lactose $e^{41}$ and not all avirulent $E$ histolytica mutants with a reduced ability to bind $\mathrm{CHO}$ cells are deficient in adherence to red blood cells. ${ }^{42}$

\section{Target cell killing}

One of the most studied properties of $E$ histolytica (and the one which gives it its name) is its ability to destroy tissues. The killing of nucleated mammalian cells is an essential first step in this process. Although the number of studies is tiny, it seems that $E$ dispar largely lacks the ability to kill tissue derived cells, ${ }^{364344}$ however, when the targets were neutrophils Bos $^{45}$ found no difference between "patient" and "carrier" strains; Leippe et $a l^{46}$ reported that $E$ dispar had about one third of the ability of $E$ histolytica. As for cytotoxic mechanisms, the problem is not finding one, but understanding why there are so many.

It is clear that although cytotoxicity is contact dependent, ${ }^{47}$ the GIL is involved in killing as well as adherence. Even if adherence in the presence of galactose is brought about by centrifugation, CHO cells are not killed ${ }^{48}$ and a monoclonal antibody directed against epitope 1 actually decreases cytotoxicity. ${ }^{49}$ However, affinity purified lectin itself does not kill $\mathrm{CHO}$ cells, despite causing a rise in intracellular calcium concentrations. ${ }^{49}$ An irreversible increase (about 20-fold) in the intracellular concentration of this ion in CHO cells occurs within seconds of contact with live trophozoites although cell death occurs only five to 15 minutes later. Pretreatment of target cells with EDTA or verapamil prevents this effect, which is also inhibited by galactose.$^{50}$ Lectin-target cell contact also leads to an increase in cytokine (interleukin-8) production, probably mediated via intracellular $\mathrm{Ca}^{2+}$ concentrations. ${ }^{51}$

These results suggest a signalling role for GIL, rather than a directly lethal one and this is not unreasonable because: (1) the predicted amino acid sequence of the heavy subunit is compatible with a membrane spanning location $^{52}{ }^{53}$; (2) each published $h g l$ sequence contains several potential phosphorylation sites; (3) there is evidence for the participation of parasite protein kinase $C$ in the cytotoxic process $^{54}$; and (4) adherence of liposomes containing a variety of glycosphingolipids bearing glycans with galactose and $\mathrm{N}$-acetyl galactosamine termini (presumably involving binding to the GIL) stimulates rapid polymerisation of $E$ histolytica actin. ${ }^{55}$

The message that contact has been established presumably causes the amoeba to activate a specific killing mechanism; several have been suggested and will be discussed later. It has also been suggested that target cells may actually be ordered to commit suicide. There is very preliminary evidence that $E$ histolytica induces apoptosis ${ }^{56}$ and that GIL is transferred to the target cell following adherence. ${ }^{57}$ It is not know whether these two processes are linked.
Of the amoeba's own putative killing mechanisms, by far the best studied are the family of pore forming peptides known collectively as amoebapores. Molecules of this class with molecular masses of $30^{58} 5913-15^{6061}$ and 8 $\mathrm{kDa}^{62}$ have been described but only the last has been investigated intensively and sequenced and is the one usually meant when amoebapore is discussed. Whether the larger molecular masses represent polymers or aggregates of amoebapore (or simply anomalous migration in gels) is not definitely known, but they may well do so. Amoebapore (actually a mixture of at least three isoforms) has recently been reviewed extensively ${ }^{6364}$ and I shall only consider here whether the molecule has a significant role in killing nucleated target cells. Two facts suggest that it does not: bacteria are killed by low concentrations $(2 \mu \mathrm{M})$ which do not seriously damage eukaryotic cells ${ }^{64}$; and a homologous peptide is produced by $E$ dispar. It seems reasonable to assume that the function of amoebapore is to prevent ingested bacteria from multiplying. However, higher concentrations (particularly of the minor $\mathrm{C}$ isoform) are capable of killing tumour cell lines. ${ }^{65}$ The $E$ dispar molecule is present in reduced amounts ${ }^{66}$ and is of lower specific activity, ${ }^{46}$ and amoebapore has structural similarities to natural killer (NK) $l y \sin ^{67}$ which is assumed to contribute to the cytotoxicity exhibited by NK and T cells. ${ }^{68}$ The amoebapores are apparently stored in (or as) cytoplasmic granules (together with another, lysozyme-like antibacterial protein ${ }^{69}$ ), which could be released after target cell adhesion had occurred, producing a lethally high local concentration. The original function of the molecule may have been adapted in $E$ histolytica to serve a new, aggressive role.

Other possible cytotoxic effectors include a phospholipase A enzyme, initially identified as a haemolytic activity in whole amoeba lysates, ${ }^{70} 71$ which is calcium dependent and membrane bound. ${ }^{72}{ }^{73}$ López-Revilla and SaidFernánde $z^{70}$ correlated the level of activity with virulence. A second phospholipase A enzyme was detected in the soluble fraction and is calcium independent. ${ }^{72}$ Cytotoxicity, but not adherence, was blocked by Rosenthal's inhibitor and phosphatidylcholine (inhibitors of phospholipase $\mathrm{A}_{2}$ ); destruction of the target cell membrane by the generation of lysophospholipids and free fatty acids was proposed as the mode of action of this enzyme. ${ }^{74}{ }^{75} \mathrm{~A}$ different and novel origin for the haemolytic activity of $E$ histolytica has been proposed by Hagblom et $a l^{76}$; these authors have identified three small open reading frames in the multicopy episomal circular DNA elements in which the parasite's rRNA genes are found. ${ }^{77}{ }^{78}$ When expressed in Escherichia coli haemolytic activity is produced; the expression products also react with antiwhole $E$ histolytica antiserum. These results were greeted with much scepticism because it could not be shown that the genes were actually expressed in the amoeba; however, this may now have been achieved for two of them. ${ }^{79}$ The presence of an open reading frame between (and in the opposite orientation to) two rRNA genes has also been reported from 
another protozoan (Giardia lamblia ${ }^{80}$ ). High concentrations of extracts from expressing bacteria were lethal to $\mathrm{CaCo}-2$ cells but expression in $E$ histolytica itself will need to be confirmed before they can be accepted as yet another cytotoxic effector. Whatever these peptides are, they do not seem to be related to two $25 \mathrm{kDa}$ haemolytic molecules described recently. ${ }^{81}$

\section{Proteolytic activity}

Enzymic degradation of extracellular matrix components, basement membrane proteins and connective tissue has long been considered to play a central role in tissue invasion by $E$ histolytica. $^{82}{ }^{83}$ Most, if not all, of these activities reported from in vitro studies are mediated by collagenase and cysteine proteinases, and levels of expression have been correlated widely with virulence. ${ }^{84-87}$

In 1982 Münoz et $a l^{84}$ described the destruction of human collagen films by $E$ histolytica trophozoites, showing a higher specificity for type I collagen over type III. The EDTA inhibitable, contact dependent activity was located in the membrane fraction of freeze thawed lysates and was not secreted. A second collagenolytic activity was also detected in medium conditioned by growth of the same strain. ${ }^{88}$ More recently, collagenase has been localised to dense granules and shown to be secreted actively on contact with its substrate, ${ }^{8990}$ again focusing attention on the role of contact mediated signal transduction in invasion.

Cysteine proteinases, which constitute a large proportion of the overall proteolytic activity found in whole cell lysates of axenic $E$ histolytica, ${ }^{91-93}$ have been investigated intensively. The partial purification of an acid proteinase has been reported, ${ }^{94}{ }^{95}$ but little is known of its substrate specificity, subcellular location or possible involvement in tissue destruction.

The much better known cathepsin B-like neutral cysteine proteinase is usually said to be actively secreted by trophozoites. ${ }^{96}{ }^{97}$ However, Spice and Ackers ${ }^{20}$ found that the amounts present in culture medium could be accounted for by the numbers of autolysed trophozoites. Multiple bands are found on substrate SDSPAGE gels but at present it is not clear how many should be attributed to different gene products, multiple forms of the same enzyme or purification artefacts. Levels of cysteine proteinase expression and secretion are widely regarded as key virulence determinants, ${ }^{98-100}$ although this view has been questioned. ${ }^{101}$ Quantitative analysis of mRNA showed a level of expression 10- to 100-fold higher in three $E$ histolytica isolates compared with two $E$ dispar strains. ${ }^{102}$ This finding is in broad agreement with previous comparative estimates of proteinase activity. ${ }^{98}{ }^{103}$ Citing the intracellular sorting system of yeast, Tannich et al $^{102}$ hypothesised that the over-production of a primarily intracellular proteinase by $E$ histolytica could activate a secretory pathway, thereby adventitiously conferring on it the ability to degrade extracellular tissue components and become an invasive parasite. In most cases, however, axenic cultures of $E$ histolytica have been compared with xenic ones of $E$ dispar and we have shown that the former have considerably higher levels of proteinase activity than xenic cultures of either species. ${ }^{2021}$ This suggests that, as with Dictyostelium, culture conditions can have a profound effect on the levels of expression of these enzymes (but see ${ }^{104}$ ).

Three cysteine proteinase genes have been well characterised, although a recent abstract ${ }^{104}$ has raised the total number to six. Two (possibly four) are present in both $E$ histolytica and $E$ dispar. ${ }^{102}$ Most interestingly, one (ACP1, CP3) has been claimed to be present only in $E$ histolytica, ${ }^{105}$ although later work has not confirmed this. ${ }^{106}$ The sequence of this gene is very different from those of the other two and if its uniqueness is confirmed, questions of its evolutionary origin and specific functions will need to be addressed.

\section{The later stages of invasion}

For reasons of space these can be dealt with only briefly. Amoeboid movement is clearly vital in passing from the lumen to the circulation. Phagocytosis (of killed epithelial cells and erythrocytes) is often regarded as a virulence determinant in its own right as well as a marker of a fully functional cytoskeleton. Erythrophagocytosis has been correlated with pathogenicity ${ }^{107}$ and phagocytosis deficient mutants seem to be avirulent in animal models $^{108}$; however, this has not been confirmed by more recent results. ${ }^{109} 110$ Functional studies of locomotion and phagocytosis are well under way ${ }^{55^{111-115}}$ and a number of actin binding proteins have been recognised. ${ }^{116-118}$ Genes for actin, ${ }^{119}{ }^{120}$ myosin II $^{121}$ and profilin ${ }^{122}$ have been sequenced. Although $E$ histolytica actin has a number of peculiarities-for example, the DNAse I binding site is conserved but the protein does not bind the enzyme, in general nothing exotic has been seen so far.

It seems implausible that trophozoites can reach the liver from the bowel without being taken there by the portal circulation and therefore it is axiomatic that they are not killed en route. Activation of the alternative complement pathway is an obvious non-specific, host defence mechanism and it was extremely satisfying when Reed et $a l^{123}$ showed that while all $E$ dispar isolates (and old, laboratory adapted $E$ histolytica isolates in axenic culture) were lysed, freshly isolated strains of $E$ histolytica in xenic culture were apparently largely resistant. This fact alone could have been enough to explain the non-invasiveness of $E$ dispar. The mechanism of resistance is not understood fully but seems to be linked to the cleavage of C3 by the parasite's cysteine proteinase. ${ }^{124} \mathrm{~A}$ recent review ${ }^{125}$ should be consulted for more details. Perhaps not surprisingly the ubiquitous GIL also seems to be involved; the molecule shares sequence similarities and antigenic cross-reactivity with the human complement regulatory protein $\mathrm{CD} 59^{126}$ and purified GIL caused $90 \%$ inhibition of $E$ histolytica lysis mediated by C $5 b-9 .{ }^{127}$ 
This logically pleasing picture has been spoiled by the studies of Hamelmann et al. ${ }^{128} 129$ These authors found that non-pathogenic isolates (that is, $E$ dispar) were nearly unaffected by exposure to alternative pathway activation; freshly isolated pathogenic strains ( $E$ histolytica) were susceptible to lysis and became more so on long term cultivation, with or without bacteria. ${ }^{128}{ }^{129} E$ histolytica acquired complement resistance on hamster liver passage or on growth in media containing increasing concentrations of normal human serum, apparently as a result of the presence of trypsin sensitive surface molecule(s). ${ }^{130}$ Genes specific for the resistant phenotype have been isolated by subtractive hybridisation. ${ }^{131}$ There seems to be a conflict between the results obtained by the two groups which needs to be resolved before the role of complement resistance in invasiveness can be assessed.

The events which occur when $E$ histolytica trophozoites reach the liver are almost completely unknown, not least because we have no animal model in which spontaneous spread from the intestine to that organ occurs. We do not know whether specific binding or random lodgment takes place; whether the amoeba, which certainly metabolises oxygen in vitro, also utilises it in vivo; or whether it flourishes only in small anoxic areas produced by earlier injury ${ }^{132}$; why men are so much more frequently affected than women; or what proportion of hepatic abscesses (if any) resolve spontaneously is uncertain. (The event appears superficially similar to tumour metastasis and several groups are trying to see if the vast knowledge of that process can shed any light on amoebiasis ${ }^{133}{ }^{134}$.)

\section{Why?}

Perhaps most curiously of all, we do not know why $E$ histolytica invades. Intestinal amoebae which do not invade are generally much more commonly found in parasitological surveys and $E$ histolytica is absent from some populations (for example, male homosexuals in developed countries except Japan) in which other intestinal protozoa are common. Transmission seems to be exclusively via the resistant cysts but diarrhoea results in the appearance of fragile trophozoites (and presumably fewer cysts) in the faeces; no onward transmission from an hepatic abscess seems to be possible. Hepatic invasion may well be an accidental, unfavourable and relatively rare consequence of the ability to invade the gut wall (although the existence of specific, hepatotropic strains which pass straight to the liver has also been suggested ${ }^{135}$ ). However, in a recent careful review Clark ${ }^{136}$ could not identify any obvious evolutionary benefits from the ability to penetrate the intestinal mucosa. He suggests that humans may be an abnormal host for $E$ histolytica, to which it has only recently transferred from, say, a ground dwelling Old World primate. There is no better alternative theory available at present. Those of us who continue to hope that invasiveness will eventually turn out to be adaptive can only be grateful that the same author, by finally persuading $E$ dispar to grow axenically, ${ }^{137}$ has provided us with the ideal tool with which to tackle the problem.

Part of the work described in this article was supported by the European Commission's Avicenne Programme. I am grateful to Drs I Bruchhaus, L S Diamond, T F H G Jackson, and M Leippe for clarifying a number of points, and to Dr C G Clark for many helpful discussions and for critically reading a draft of this paper.

1 Kean BH. A history of amebiasis. In: Ravdin JI, ed. Amebia sis: Human infection by Entamoeba histolytica. New York: John Wiley, 1988:1-10.

2 Ravdin II (ed). Amebiasis: Human infection by Entamoeba histolytica. New York: John Wiley, 1988.

3 Bruckner DA. Amebiasis. Clin Microbiol Rev 1992;5:356 69.

4 Horstmann RD, Leippe M, Tannich E. Recent progress in the molecular biology of Entamoeba histolytica. Trop Med Parasitol 1992;43:213-18.

5 Kelsall BL, Ravdin JI. Amebiasis: human infection with Entamoeba histolytica. Prog Clin Parasitol 1994;4:27-54.

6 Ravdin JI. Amebiasis. Clin Infect Dis 1995;20:1453-66.

7 Walsh JA. Problems in recognition and diagnosis of amebiasis: estimation of the global magnitude of morbidity and mortality. Rev Infect Dis 1986;8:228-38.

8 Martínez-Palomo A, González-Robles A, de la Torre M. Selective agglutination of pathogenic strains of Entamoeba histolytica induced by Con A. Nature New Biol 1973; 245:186-7.

9 Diamond LS, Clark CG. A redescription of Entamoeba histolytica Schaudinn, 1903 (Emended Walker, 1911) separating it from Entamoeba dispar Brumpt, 1925. f Euk Microbiol 1993;40:340-4.

10 Clark CG, Diamond LS. Pathogenicity, virulence and Entamoeba histolytica. Parasitol Today 1994;10:46-7.

11 Gladstone GP. In: Florey HW, ed. General pathology. 4th edn. London: Lloyd Luke (Medical Books), 1970:823-34.

12 Diamond LS. Amebiasis: a problem solved. What now? Bernardo Sepulveda Memorial lecture. Arch Med Res 1992;23:157-61.

13 Mukherjee RM, Mazumdar M, Maitra TK, Jalan KN. Virulence of nonpathogenic zymodemes of Entamoeba histolytica isolates from asymptomatic subjects in Calcutta, India. Braz F Med Biol Res 1992;25:899-903.

14 Sargeaunt PG. Zymodemes of Entamoeba histolytica. In Ravdin JI, ed. Amebiasis: Human Infection by Entamoeba histolytica. New York: John Wiley, 1988:370-87.

15 Jackson TFHG, Gathiram V, Simjee AE Seroepidemiological study of antibody responses to the zymodemes of Entamoeba histolytica. Lancet 1985;i:716-19.

16 Gathiram V, Jackson TFHG. A longitudinal study of asymptomatic carriers of pathogenic zymodemes of Entamoeba histolytica. S Afr Med $\mathcal{F}$ 1987;72:669-72.

17 Irusen EM, Jackson TFHG, Simjee AE Asymptomatic intestinal colonization by pathogenic Entamoeba histolytica in amebic liver abscess: prevalence, response to therapy, and pathogenic potential. Clin Infect Dis 1992, 14:889-93.

18 Clark CG, Diamond LS. The Laredo strain and other 'Entamoeba histolytica-like' amoebae are Entamoeba moshkovskii. Mol Biochem Parasitol 1991;46:11-18.

19 Diamond LS. Lumen dwelling protozoa: Entamoeba, Trichomonads, and Giardia. In: Jensen JB, ed. In vitro Cultivation of protozoan Parasites. Boca Raton, FL: CRC Press, 1983:65-109.

20 Spice WM, Ackers JP. The effect of axenic versus xenic culture conditions on the total and secreted proteolytic activity of Entamoeba histolytica strains. Arch Med Res 1992;23:91-3.

21 Spice WM, Ackers JP. Influence of bacteria on electrophoretic proteinase patterns of Entamoeba histolytica isolates. Int $\mathcal{F}$ Parasitol 1993;23:671-4.

22 Prasad R Tola M, Bhattacharya S, Sharma MP Bhattacharya A. Recognition of Entamoeba histolytica lipophosphoglycan by a strain-specific monoclonal antibody and human immune sera. Mol Biochem Parasitol 1992;56:279_ 87.

23 Blakely P, Sargeaunt PG, Reed SL. An immunogenic $30-\mathrm{kDa}$ surface antigen of pathogenic clinical isolates of Entamoeba histolytica. F Infect Dis 1990;162:949-54.

24 Bracha R, Mirelman D. Virulence of Entamoeba histolytica trophozoites. Effects of bacteria, microaerobic conditions, and metronidazole. $\mathcal{F}$ Exp Med 1984;160:353-68.

25 Walker EL, Sellards WS. Experimental entamoebic dysentery. Phillipine $\mathcal{F}$ Sci B Trop Med 1913;8:253-31.

26 Ramakrishnan G, Ragland BD, Purdy JE, Mann BJ. Physical mapping and expression of gene families encoding the $N$-acetyl D-galactosamine adherence lectin of Entamoeba histolytica. Mol Microbiol 1996;19:91-100.
Chadee K, Petri WA Jr, Innes DJ, Ravdin JI. Rat and human colonic mucins bind to and inhibit adherence lectin of colonic mucins bind to and inhibit adherence lectin

28 Chadee K, Meerovitch E Entamoeba histolytica: early progressive pathology in the cecum of the gerbil (Meriones unguiculatus). Am f Trop Med Hyg 1985;34:283-91.

29 Chadee K, Keller K, Forstner J, Innes DJ, Ravdin JI. Mucin and nonmucin secretagogue activity of Entamoeba histolytica and cholera toxin in rat colon. Gastroenterology 1991;100:986-97. 
30 Keller K, Olivier $\mathbf{M}$, Chadee $\mathrm{K}$. The fast release of mucin secretion from human colonic cells induced by Entamoeba histolytica is dependent on contact and protein kinase $C$ activation. Arch Med Res 1992;23:217-21.

31 Petri WA Jr, Snodgrass TL, Jackson TFHG, Gathiram V, Simjee AE, Chadee $\mathrm{K}$, et al. Monoclonal antibodies directed against the galactose-binding lectin of Entamoeba histolytica enhance adherence. FImmunol 1990;144:4803

32 Petri WA Jr, Jackson TFHG, Gathiram V, Kress K, Saffer LD, Snodgrass TL, et al. Pathogenic and nonpathogenic strains of Entamoeba histolytica can be differentiated by monoclonal antibodies to the galactose-specific adherence monoclonal antibodies to the galacto

33 Stanley SL Jr, Huizenga $\mathrm{H}, \mathrm{Li}$ E. Isolation and partial characterization of a surface glycoconjugate of Entamoeba histolytica. Mol Biochem Parasitol 1992;50:127-38.

34 Arroyo R, Orozco E. Localization and identification of an Entamoeba histolytica adhesin. Mol Biochem Parasito 1987;23:151-8.

35 Rigothier MC, Garcia-Rivera G, Guaderrama M, Orozco E Purification and functional characterization of the 112 $\mathrm{kDa}$ adhesin of Entamoeba histolytica. Arch Med Res 1992;23:239-41.

36 Vargas MA, Isibasi A, Kumate J, Orozco E. Non-pathogenic Entamoeba histolytica: functional and biochemical characterization of a monoxenic strain. Mol Biochem Parasito 1990;40:193-201.

37 Meza I, Cazares F, Rosales-Encina JL, Talamás-Rohana $P$ Rojkind M. Use of antibodies to characterize a 220 kilodalton surface protein from Entamoeba histolytica. $f$ Infect Dis 1987;156:798-805.

38 Rosales-Encina JL, Meza I, Lopez De Leon A, TalamásRohana P, Rojkind M. Isolation of a 220 -kilodalton protein with lectin properties from a virulent strain of protein with lectin properties from a virulent strain

39 Smith JM, Meerovitch E Specificity of iron requirements of Entamoeba histolytica in vitro. Arch Invest Med (Mex) 1982;13(Suppl 3):63-9.

40 Diamond LS, Clark CG, Cunnick CC. YI-S, a casein-free medium for axenic cultivation of Entamoeba histolytica, related Entamoeba, Giardia intestinalis and Trichomonas vaginalis. f Euk Microbiol 1995;42:277-8.

41 Cano-Mancera $R$, López-Revilla $R$. Inhibition of the adhesion of Entamoeba histolytica trophozoites to human erythrocytes by carbohydrates. Parasitol Res 1987;74:1822.

42 Orozco E, Rodriquez MA, Murphy CF, Salata RA, Petri WA $\mathrm{Jr}$, Smith RD, et al. Entamoeba histolytica: cytopathogenicity and lectin activity of avirulent mutants. Exp Parasitol 1987;63:157-65.

43 Kollaritsch H, Graf J, Stemberger H, Krumpolz B, Binder $M$, Scheiner $\mathrm{O}$, et al. Interaction of different strains of Entamoeba histolytica with target cells: characterization of electrophysiological and morphological features. Immunobiology 1989;179:190-201.

44 Bürchard GD, Prange G, Mirelman D. Interaction of various Entamoeba histolytica strains with human intestinal cell lines. Arch Med Res 1992;23:193-5.

45 Bos HJ. The problem of pathogenicity in parasitic Entamoeba. Acta Leiden 1973;40:11-111.

46 Leippe M, Bahr E, Tannich E, Horstmann RD. Comparison of pore-forming peptides from pathogenic and nonpathogenic Entamoeba histolytica. Mol Biochem Parasitol 1993 59:101-9.

47 Ravdin JI, Croft BY, Guerrant RL. Cytopathogenic mechanis

48 Ravdin JI, Guerrant RL. Role of adherence in cytopathogenic mechanisms of Entamoeba histolytica. Study with mammalian tissue culture cells and human erythrocytes. $f$ Clin Invest 1981;68:1305-13.

49 Saffer LD, Petri WA Jr. Role of the galactose lectin of Entamoeba histolytica in adherence-dependent killing of mammalian cells. Infect Immun 1991;59:4681-3.

50 Ravdin JI, Moreau F, Sullivan JA, Petri WA Jr, Mandell GL Relationship of free intracellular calcium to the cytolytic activity of Entamoeba histolytica. Infect Immun 1988, 56:1505-12.

51 Eckmann L, Reed SL, Smith JR, Kagnoff MF. Entamoeba histolytica trophozoites induce an inflammatory cytokine response by cultured human cells through the paracrine response by cultured human cells through the paracrine
action of cytolytically released Interleukin-1-alpha. $\mathcal{f}$ Clin action of cytolytically releas
Invest 1995;96:1269-79.

52 Mann BJ, Torian BE, Vedvick TS, Petri WA Jr. Sequence of a cysteine-rich galactose-specific lectin of Entamoeba histolytica. Proc Natl Acad Sci USA 1991;88:3248-52.

53 Tannich E, Ebert F, Horstmann RD. Primary structure of the $170-\mathrm{kDa}$ surface lectin of pathogenic Entamoe histolytica. Proc Natl Acad Sci USA 1991;88: 1849-53.

54 Weikel CS, Murphy CF, Orozco E, Ravdin JI. Phorbol esters specifically enhance the cytolytic activity

55 Bailey GB, Nudelman ED, Day DB, Harper CF, Gilmour JR. Specificity of glycosphingolipid recognition by EntamOet

56 Ragland BD, Ashley LS, Vaux DL, Petri WA Jr. Entamoeba histolytica: target cells killed by trophozoites undergo DNA fragmentation which is not blocked by Bcl-2. Exp Parasitol 1994;79:460-7.

57 Leroy A, Debruyne G, Mareel M, Nokkaew C, Bailey G, Nelis H. Contact dependent transfer of the galactosespecific lectin of Entamoeba histolytica to the lateral surface of enterocytes in culture. Infect Immun 1995 63:4253-60.
58 Young JD, Young TM, Lu LP, Unkeless JC, Cohn ZA Characterization of a membrane pore-forming protein from Entamoeba histolytica. F Exp Med 1982;156:167790 .

59 Young JD, Cohn ZA. Molecular mechanisms of cytotoxicity mediated by Entamoeba histolytica: characterization of a pore-forming protein (PFP). 7 Cell Biochem 1985;29:299 308.

60 Lynch EC, Rosenberg I, Gitler C. An ion channel forming protein produce

D, Loew LM, Gitler C. Isolation, characterization and partial purification of a transferable
membrane channel (amoebapore) produced by Entammembrane channel (amoebapore) produced by Entam-

62 Leippe M, Ebel S, Schoenberger OL, Horstmann RD Muller Eberhard HJ. Pore-forming peptide of pathogeni Entamoeba histolytica. Proc Natl Acad Sci USA 1991 88:7659-63.

63 Leippe M, Andra J, Nickel R, Tannich E, Muller Eberhard HJ. Amoebapores, a family of membranolytic peptides from cytoplasmic granules of Entamoeba histolytica: isolation, primary structure, and pore formation in bacterial cytoplasmic membranes. Mol Microbiol 1994;14:895-904.

64 Leippe M, Muller Eberhard HJ. The pore-forming peptide of Entamoeba histolytica, the protozoan parasite causing of Entamoeba histolytica, the protozoan parasi

65 Berninghausen O, Leippe M. Killing of human cells by amoebapores, pore-forming peptides of Entamoeba histolytica [abstract]. European Conference on Tropical Medicine, Hamburg. 1995;L55:143.

66 Caballero-Salcedo A, Viveros-Rogel M, Salvatierra B, Tapia-Conyer R, Sepulveda-Amor J, Gutierrez G, et al. Seroepidemiology of amebiasis in Mexico. Am 7 Trop Med Hyg 1994;50:412-19.

67 Leippe M. Ancient weapons: NK-lysin, is a mammalian homolog to pore-forming peptides of a protozoan parasite. Cell 1995;83:17-18.

68 Andersson M, Gunne H, Agerberth B, Boman A, Bergman $\mathrm{T}$, Sillard $\mathrm{R}$, et al. NK-lysin, a novel effector peptide of cytotoxic $T$ and NK cells. Structure and CDNA cloning of the porcine form, induction by interleukin 2 , antibacteria and antitumour activity. EMBO $\mathrm{f} 1995 ; 14: 1615-25$.

69 Jacobs T, Leippe M. Purification and molecular cloning of a major antibacterial protein of the protozoan parasite Entamoeba histolytica with lysozyme-like properties. Eur f Biochem 1995;231:831-8.

70 López-Revilla R, Said-Fernández S. Cytopathogenicity of Entamoeba histolytica: hemolytic activity of trophozoite homogenates. Am F Trop Med Hyg 1980;29:209-12.

71 Said-Fernández S, López-Revilla R. Subcellular distribution and stability of the major hemolytic activity of Entamoeba histolytica trophozoites. $Z$ Parasitenkd 1982;67:249-54.

72 Long Krug SA, Fischer KJ, Hysmith RM, Ravdin JI. Phospholipase A enzymes of Entamoeba histolytica: description and sub

73 Vargas-Villarreal J, Martinez-Rodriguez H, Castro-Garza JE, Mata-Cárdenas BD, Gonzalez-Garza MT, SaidFernández S. Identification of Entamoeba histolytica intracellular phospholipase $A$ and lysophospholipase L1 intracellular phospholipase A and lys

74 Ravdin JI, Murphy CF, Guerrant RL, Long Krug SA. Effect of antagonists of calcium and phospholipase $A$ on the cytopathogenicity of Entamoeba histolytica. $\mathcal{F}$ Infect Dis 1985;152:542-9.

75 Said-Fernández S, López-Revilla R. Free fatty acids released from phospholipids are the major heat-stable hemolytic factor of Entamoeba histolytica trophozoites. Infect Impiun 1988;56:874-9.

76 Jansson A, Gillin F, Kagardt U, Hagblom P. Coding of hemolysins within the ribosomal RNA repeat on a plasmid hemolysins within the ribosomal RNA repeat on a p

77 Bhattacharya S, Bhattacharya A, Diamond LS, Soldo AT. Circular DNA of Entamoeba histolytica encodes ribosomal RNA. F Protozool 1989;36:455-8.

78 Huber M, Koller B, Gitler C, Mirelman D, Revel M, Rozenblatt S, et al. Entamoeba histolytica ribosomal RNA genes are carried on palindromic circular DNA molecules. Mol Biochem Parasitol 1989;32:285-96.

79 Hagblom P, Taha S, Kagardt U. Hemolysin genes in Entam oeba histolytica [abstract]. Molecular Parasitology Meeting, Woods Hole 1995:455.

80 Upcroft JA, Healey A, Mitchell R, Boreham PF, Upcroft P. Antigen expression from the ribosomal DNA repeat unit of Giardia intestinalis. Nucleic Acids Res 1990;18:7077-81.

81 Rosales-Encina JL, Schlie-Guzmán MA, JiménezDelgadillo B, Talamás-Rohana P, Matluk MR. Purification and partial characterization of an hemolytic activity from Entamoeba histolytica. Arch Med Res 1992;23:243-8.

82 Neal RA. Enzymic proteolysis by Entamoeba histolytica: biochemical characteristics and relationships with invasiveness. Parasitology 1960;50:531-50.

83 Jarumilinta R, Maegraith BG. Enzymes of Entamoeba histolytica. Bull World Health Organ 1969;41:269-73.

84 Münoz ML, Calderón J, Rojkind $M$. The collagenase of Entamoeba histolytica. $₹$ Exp Med 1982;155:42-51

85 Gadasi H, Kobiler D. Entamoeba histolytica: correlation between virulence and content of proteolytic enzymes. Exp Parasitol 1983;55:105-10.

86 Lushbaugh WB, Hofbauer AF, Kairalla AA, Cantey JR Pittman FE. Relationship of cytotoxins of axenically cultivated Entamoeba histolytica to virulence. Gastroenterology 1984;86: 1488-95. 
87 Keene WE, Hidalgo ME, Orozco E, McKerrow JH. Entamoeba histolytica: correlation of the cytopathic effect of virulent trophozoites with secretion of a cysteine proteinase. Exp Parasitol 1990;71:199-206.

88 Gadasi H, Kessler E. Correlation of virulence and collagenolytic activity in Entamoeba histolytica. Infect Immun 1983;39:528-31.

89 Münoz ML, Lamoyi E, Leon G, Tovar R, Perez Garcia J, de la Torre M, et al. Antigens in electron-dense granules from Entamoeba histolytica as possible markers for pathogenic ity. 7 Clin Microbiol 1990;28:2418-24.

90 Serrano JJ, de la Garza M, Moreno MA, Tovar R, Leon G, Tsutsumi V, et al. Entamoeba histolytica: electron-dens granule secretion, collagenase activity and virulence are altered in the cytoskeleton mutant BG-3. Mol Microbiol 1994;11:787-92.

91 Avila EE, Sanchez-Garza M, Calderón J. Entamoeba histolytica and E. invadens: sulfhydryl-dependent proteolytic activity. F Protozool 1985;32:163-6.

92 Pérez Montfort R, Ostoa-Saloma P, Velazquez-Medina I Montfort I, Becker I. Catalytic classes of proteinases of Entamoeba histolytica. Mol Biochem Parasitol 1987;26:8797.

93 Schulte W, Scholze H. Action of the major protease from Entamoeba histolytica on proteins of the extracellula matrix. F Protozool 1989;36:538-43.

94 McLaughlin J, Faubert G. Partial purification and some properties of a neutral sulfhydryl and an acid proteinase from Entamoeba histolytica. Can $\mathcal{f}$ Microbiol 1977 23:420-5.

95 Scholze H, Werries E A weakly acidic protease has a powerful proteolytic activity in Entamoeba histolytica. Mo Biochem Parasitol 1984;11:293-300.

96 Keene WE, Petitt MG, Allen S, McKerrow JH. The major neutral proteinase of Entamoeba histolytica. 7 Exp Med 1986;163:536-49.

97 Leippe $M$, Sievertsen HJ, Tannich E, Horstmann RD. Spontaneous release of cysteine proteinases but not of pore-forming peptides by viable Entamoeba histolytica. Parasitology 1995;111:569-74.

98 Reed SL, Keene WE, McKerrow JH. Thiol proteinase expression and pathogenicity of Entamoeba histolytica. $\mathscr{f}$ Clin Microbiol 1989;27:2772-7.

99 Stanley SL Jr, Zhang T, Rubin D, Li E. Role of the Entamoeba histolytica cysteine proteinase in amebic liver abscess formation in severe combined immunodeficient mice. Infect Immun 1995;63:1 1587-90.

100 Scholze H, Tannich E Cysteine endopeptidases of Entamoeba histolytica. Methods Enzymol 1994;244:512-23.

101 Montfort I, Olivos A, Pérez-Tamayo R. Phagocytosis and proteinase activity are not related to pathogenicity of $E$. histolytica. Parasitol Res 1993;79:160-2.

102 Tannich E, Scholze H, Nickel R, Horstmann RD. Homologous cysteine proteinases of pathogenic and nonpathogenic Entamoeba histolytica. Differences in structure and expression. $\mathcal{F}$ Biol Chem 1991;266:4798-803.

103 De Meester F, Shaw E, Scholze H, Stolarsky T, Mirelman D. Specific labelling of cysteine proteinases in pathogenic and nonpathogenic Entamoeba histolytica. Infect Immun 1990;58:1396-401.

104 Bruchhaus I. Cysteine proteases of Entamoeba histolytica and Entamoeba dispar [abstract]. European Conference on Tropical Medicine, Hamburg 1995:L73.

105 Reed S, Bouvier J, Pollack AS, Engel JC, Brown M, Hirata $\mathrm{K}$, et al. Cloning of a virulence factor of Entamoeba histolytica. Pathogenic strains possess a unique cysteine proteinase gene. $\mathcal{F}$ Clin Invest 1993;91:1532-40.

106 Bruchhaus I, Tannich E. A gene highly homologous to ACP1 encoding cysteine proteinase 3 in Entamoeb histolytica is present and expressed in E. dispar. Parasitol Res 1996;82: 189-92.

107 Trissl D, Martinez-Palomo A, de la Torre M, de la Hoz R Suarez E. Surface properties of Entamoeba: increased rates of human erythrocyte phagocytosis in pathogenic strains. 7 Exp Med 1978;148:1137-43.

108 Orozco E, Guarneros G, Martínez-Palomo A, Sanchez T. Entamoeba histolytica. Phagocytosis as a virulence factor f Exp Med 1983;158:1511-21.

109 Tsutsumi V, Ramirez-Rosales A, Lanz-Mendoza H, Shibayama M, Chávez B, Rangel Lopez E, et al. Entamoeba histolytica: erythrophagocytosis, collagenolysis, and liver abscess production as virulence markers. Trans $R$ Soc Trop Med Hyg 1992;86:170-2.

110 Montfort I, Pérez-Tamayo R. Is phagocytosis related to virulence in Entamoeba histolytica Schaudinn, 1903? Parasitol Today 1994;10:271-3.

111 Bailey GB, Day DB, Nokkaew C, Harper CC. Stimulation by target cell membrane lipid of actin polymerization and phagocytosis by Entamoeba histolytica. Infect Immun phagocytosis by

112 Talamás-Rohana $\mathrm{P}$, Meza I. Interaction between pathogenic amebas and fibronectin: substrate degradation an changes in cytoskeleton organization. F Cell Biol 1988; 106: $1787-94$.
113 Rahim Z, Raymond-Denise A, Sansonetti P, Guillén N. Localization of myosin heavy chain $\mathrm{A}$ in the human pathogen Entamoeba histolytica. Infect Immun 1993;61:104854.

114 Espinosa-Cantellano M, Martínez-Palomo A. Entamoeba histolytica: mechanism of surface receptor capping. Exp Parasitol 1994;79:424-35.

115 Santiago A, Carbajal ME, Benitez-King G, Meza I Entamoeba histolytica: PKC transduction pathway activation in the trophozoite-fibronectin interaction. Exp Parasitol 1994;79:436-44.

116 Bailey GB, Shen PS, Beanan MJ, McCoomer NE. Actin associated proteins of Entamoeba histolytica. Arch Med Res 1992;23:129-32.

117 Vázquez-Prado J, Meza I. Fibronectin "receptor" in Entamoeba histolytica: purification and association with the cytoskeleton. Arch Med Res 1992;23:125-8.

118 Vazquez J, Franco E, Reyes G, Meza I. Characterization of adhesion plates induced by the interaction of Entamoeba histolytica trophozoites with fibronectin. Cell Motil Cytoskeleton 1995;32:37-45.

119 Edman U, Meza I, Agabian N. Genomic and cDNA actin sequences from a virulent strain of Entamoeba histolytica. Proc Natl Acad Sci USA 1987;84:3024-8.

120 Huber M, Garfinkel L, Gitler C, Mirelman D, Revel M, Rozenblatt S. Entamoeba histolytica: cloning and characterization of actin cDNA. Mol Biochem Parasitol 1987; 24:227-35.

121 Raymond-Denise A, Sansonetti P, Guillén N. Identification and characterization of a myosin heavy chain gene $(m h c A)$ from the human parasitic pathogen Entamoeba histolytica. Mol Biochem Parasitol 1993;59:123-31.

122 Binder M, Ortner S, Erben H, Scheiner O, Wiedermann $\mathrm{G}$, Valenta $\mathrm{R}$, et al. The basic isoform of profilin in pathogenic Entamoeba histolytica-cDNA cloning, heterologous expression and actin-binding properties. Eur $\mathcal{f}$ Biochem 1995;233:976-81.

123 Reed SL, Sargeaunt PG, Braude AI. Resistance to lysis by human serum of pathogenic Entamoeba histolytica. Tran $R$ Soc Trop Med Hyg 1983;77:248-53.

124 Reed SL, Gigli I. Lysis of complement-sensitive Entamoeba histolytica by activated terminal complement components. Initiation of complement activation by an extracellular neutral cysteine proteinase. F Clin Invest 1990; 86:1815-22.

125 Reed SL. New concepts regarding the pathogenesis of amebiasis. Clin Infect Dis 1995;21:S182-5.

126 Flores-Romo L, Tsutsumi V, Estrada-Garcia T, Shibayama $\mathrm{M}$, Aubry JP, Bacon KB, et al. CD59 (protectin) molecule, resistance to complement, and virulence of Entamoeb histolytica. Trans $R$ Soc Trop Med Hyg 1994;88:116-17.

127 Braga LL, Ninomiya H, McCoy JJ, Eacker S, Wiedmer T, Pham C, et al. Inhibition of the complement membrane attack complex by the galactose-specific adhesion of Entamoeba histolytica. $\mathcal{F}$ Clin Invest 1992;90:1131-7.

128 Hamelmann C, Foerster B, Bürchard GD, Horstmann $\mathrm{RD}$. Lysis of pathogenic and nonpathogenic Entamoeba histolytica by human complement: methodological analysis. Parasite Immunol 1992;14:23-35.

129 Hamelmann C, Foerster B, Bürchard GD, Shetty N, Horstmann RD. Induction of complement resistance in cloned pathogenic Entamoeba histolytica. Parasite Immunol 1993;15:223-8.

130 Hamelmann C, Urban B, Foerster B, Horstmann RD Complement resistance of pathogenic Entamoeba histolytica mediated by trypsin-sensitive surface compotolytica mediated by trypsin-sensitive

131 Urban B, Blasig C, Hamelmann C, Horstmann RD. Identification of genes specifically expressed in E. histolytica resistant to lysis by the alternative complement pathway [abstract]. European Conference on Tropical Medicine, Hamburg 1995;L130:152.

132 Gogler $\mathrm{H}$, Knight $\mathrm{R}$. The effect of hepatic injury upon the development of amoebic liver abscess in hamsters. Ann Trop Med Parasitol 1974;68:177-85.

133 Orozco E, Benitez-Bribiesca L, Hernandez R. Invasion and metastasis mechanisms in Entamoeba histolytica and cancer cells. Some common cellular and molecular features. cer cells. Some common cell
Mutat Res 1994;305:229-39.

134 Leroy A, Mareel M, De Bruyne G, Bailey G, Nelis H. Metastasis of Entamoeba histolytica compared to colon cancer: One more step in invasion. Invasion Metastasis 1994;14:177-91.

135 Charmot G. Do hepatotropic strains of Entamoeba histolytica exist? Bull Soc Pathol Exot Filiales 1980;73:40510.

136 Clark CG. Evolution of virulence in Entamoeba histolytica. Trop Dis Bull 1995;92:R147-55.

137 Clark CG. Axenic cultivation of Entamoeba dispar Brumpt 1925, Entamoeba insolita Geiman and Wichterman 1937 and Entamoeba ranarum Grassi 1879. F Euk Microbiol 1995;42:590-3. 